\title{
Systematic Approach to Evaluate the Potential of Dexmedetomidine in Attenuating the Pressor Response and the Quality of Intubation during Laryngoscopy
}

\author{
Neha Varhney ${ }^{1}$, Tapan Agrawal ${ }^{2}$, Roma Sharma ${ }^{3}$, Sanjeev Kumar Nangia ${ }^{4}$, Pramod Mangwana $^{5}$ \\ ${ }^{1}$ Department of Anesthesiology, Saraswati Medical College, Unnao (U.P) India, 209859, ${ }^{2}$ Park Hospital, Gurugram, Haryana, India, 122001, ${ }^{3}$ Mata Chanan \\ Devi Hospital, C-1, Janakpur, New Delhi - 110058, ${ }^{4}$ Shroff Eye Centre, A-7, Kailash Colony Road, Block - A, Kailash Colony, Greater Kailash, New Delhi, \\ $110048,{ }^{5}$ Senior Consultant \& Head, Department of Anaesthesiology, Mata Chanan Devi Hospital, C-1, Janakpur, New Delhi - 110058
}

\section{Abstract}

Background: Onset of hemodynamic changes is often associated with procedures such as laryngoscopy and tracheal intubation. This poses an increased risk of fatality in high-risk patients with diseases such as cardiovascular diseases. Several attempts utilizing singular parameters have been used to combat this clinical manifestation. In this study, we have used a holistic approach, in combination with the pre-recommended parameters, to attenuate the pressor responses during the procedure. Subjects and Methods: Sixty adult patients were randomized into two groups, receiving two different doses of dexmedetomidine $(0.5 \mu \mathrm{g}$ or $1 \mu \mathrm{g})$ per kilogram of the bodyweight. In addition, the quality of the intubation was also assessed using the scoring system adapted from McNeil et al., 2000. Longitudinal monitoring of various physiological parameters such as systolic blood pressure (SBP), diastolic blood pressure (DBP), mean arterial pressure (MAP), heart rate (HR) and O2 saturation ( $\mathrm{SpO} 2)$ was performed at four different time points during the procedure. Results: Our results revealed that dexmedetomidine administration results in a transient decrease in these parameters in the patients from both the groups, with more prominent effects in the Group I patients, received $1 \mu \mathrm{g} / \mathrm{kg}$ of dexmedetomidine. Moreover, at time-point T3 (60 sec after intubation), a transient increase was observed in almost all the tested parameters. The assessment of the intubating conditions revealed no significant differences among the groups. Conclusion: A higher dosage of dexmedetomidine $(1 \mu \mathrm{g} / \mathrm{kg})$ showed better management of hemodynamic responses during laryngoscopy and intubation.

Keywords: Tachycardia, hypertension, pressor response, laryngoscopy, intubation.

Corresponding Author: Dr. Tapan Agrawal, MS, MCH, Park Hospital, Gurugram, Haryana, India, 122001.

Received: April 2020

Accepted: April 2020

\section{Introduction}

Increases in the heart rate and the systemic blood pressure, commonly known as pressor responses, are often associated with procedures involving laryngoscopy and endotracheal intubation in patients. Minimization of the pressor response during laryngoscopy and endotracheal intubation is critical during the procedure, particularly while treating patients with high-risk cardiovascular diseases (CVD). The manifestation of the pressor response usually occurs in the form of tachycardia and hypertension and has been shown to be one of the secondary responses of laryngoscopy and intubation that is associated with reflex sympathetic stimulation. This reflex is mediated by vagus (X) \& Glossopharyngeal (IX) cranial nerves, which carry the afferent stimulus from the epiglottis \& supraglottic region and activate the vasomotor center. As a consequence, this leads to a peripheral sympathetic adrenal response causing the release of adrenaline \& noradrenaline, resulting in the pressor responses. ${ }^{[1]}$ These responses include a rise in the pulse rate and blood pressure which is usually transient, variable and unpredictable. In the patients with end-organ decompensation, pressor responses could also lead to intracranial bleeding, ${ }^{[2]}$ dysrhythmias, ${ }^{[3]}$ acute left ventricular failure and may also result in intra-operative myocardial infarction. $^{[4]}$

During laryngoscopy and intubation, the pressor response peaks at 1-2 minutes and returns to baseline within 5-10 minutes. Several methods, including pharmacological and non-pharmacological tools, have been employed to tone down the hemodynamic responses to laryngoscopy \& endotracheal intubation. Among the non-pharmacological interventions, intubation through the usage of C-Trach laryngeal mask airway (LMA) assembly instead of intubation with direct laryngoscopy (DL) resulted in a minimal rise in the systolic blood pressure (SBP). ${ }^{[5]}$ Modified laryngoscopy procedures with relatively shorter duration as well as gentle intubation, blockade of Glossopharyngeal \& Superior laryngeal nerves have also shown to attenuate the pressor response to an extent. ${ }^{[4]}$

Several studies have employed interventions using various 
pharmacological agents to attenuate the pressor responses during laryngoscopy and intubation. Among these, induction of topical anesthesia using lignocaine, ${ }^{[6]}$ usage of narcotics such as fentanyl and alfentanil, ${ }^{[7]}$ combination of narcotic agents with anesthetic agents such as alfentanil with lidocaine and alfentanil with sevoflurane and have been implicated in reducing the pressor responses. ${ }^{[8,9]}$ Induction of deep general anesthesia by the application of such agents as well as the usage of calcium channel blockers and $\beta$-blockers such as propranolol, esmolol and analgesics such as remifentanil anesthetic adjuvants also proved to be an effective suppressor of pressor response associated with laryngoscopy and intubation. ${ }^{[10-16]}$

Selective activation of adrenergic receptors using sympathomimetic drugs ( $\alpha-2$ agonists) such as clonidine and dexmedetomidine, which attenuates the sympathetic responses, have also been shown to promote hemodynamic stability. While both clonidine and dexmedetomidine activate $\alpha-1$ and $\alpha-2$ receptors, dexmedetomidine selectively activates $\alpha-2$ adrenoceptors with a higher binding ratio of 1620:1 $(\alpha 2: \alpha 1)$ compared to $220: 1$ for clonidine $(\alpha 2: \alpha 1)$ and is shown to have better anxiolytic and analgesic properties when applied intravenously as a pre-medicant anaesthesia setting. ${ }^{[17]}$ In this study, we have used two different doses of dexmedetomidine in addition to a robust intubation condition scoring system and evaluated the pressor response during laryngoscopy in the patients belonging to ASA class I and II.

\section{Subjects and Methods}

After obtaining the Hospital Ethical Committee clearance with the letter number (9- 72/DNB/2011-13/MCDH-3125), the study was conducted at Mata Chanan Devi Hospital, New Delhi. Sixty patients, both males and females, scheduled for various elective surgical procedures requiring general anesthesia, belonging to ASA class I and II were selected for this study. Patients selected were of age group between 18 and 60 years and weight between 50 and $90 \mathrm{~kg}$. Patients who were ASA grade 3 or above and those with the history of cardiovascular, respiratory, hepatic, renal, endocrine, neurological diseases, or hypersensitivity to dexmedetomidine or clonidine, patients on sedatives, hypnotics, antidepressants and alcohol abuse were excluded from the study. Patients with anticipated difficult airway, those receiving other alpha 2 agonists like clonidine or opioids and patients on beta blockers were also excluded from the study. Last, patients in which laryngoscopy time exceeded $15 \mathrm{~s}$ were excluded from the analysis.

\section{Data Collection Technique and Tools}

All patients were provided with patient information sheet and informed consent was obtained in writing. After taking consent, thorough history was elicited. Patients were clinically examined in detail and investigated. All patients were pre-medicated with tablet alprazolam $0.5 \mathrm{mg}$ and tablet ranitidine $150 \mathrm{mg}$ orally at bedtime, the night before surgery. All patients were kept 6 hours of fasting prior to surgery. Patients were randomly divided into two groups of thirty each. Randomization was done using a computer-generated random number table (https://www.randomizer.org/). An intravenous drip was started and vital baseline parameters were noted. All the patients were premedicated with injection glycopyrrolate $0.2 \mathrm{mg}$ and inj. Midazolam $1.5 \mathrm{mg}$ IV. A partial double-blinded procedure was followed, in which the person is administering the drug and the patient both were unaware as to which group the patient belonged to. One consultant anesthesiologist prepared the intravenous (IV) infusions and coded them with different colors without revealing the dosage information of the drug in order to reduce the bias. The infusions were handed over to another anaesthetist to be administered to the patients who were unaware of the contents of the syringe but recorded the parameters that were observed in response to the drug infusions. The predetermined list of patients in each group (Group I patients receiving $1.0 \mu \mathrm{g} / \mathrm{kg}$ body weight and Group II patients receiving $0.5 \mu \mathrm{g} / \mathrm{kg}$ body weight) were assigned one of the two colored labels in the list as per the group. Patients in group I received dexmedetomidine $1.0 \mu \mathrm{g} / \mathrm{kg}$ body weight diluted in normal saline to make a solution of 10 $\mathrm{ml}$, infused intravenously over $10 \mathrm{~min}$, using a syringe pump and similarly, patients in group II received dexmedetomidine $0.5 \mu \mathrm{g} / \mathrm{kg}$ body weight diluted in normal saline to make a solution of $10 \mathrm{ml}$. The results of the study were analyzed at the end of the study and then the decoding procedure was done. The patients were also unaware of the dosage of the drug they received. Therefore, we ensured that the differences in the infusion time reduce the placebo effect on the patients to the minimum and the influence on the recorder to the least. Thiopentone $5 \mathrm{mg} / \mathrm{kg}$ was given 90 seconds after the infusion. Vecuronium $0.1 \mathrm{mg} / \mathrm{kg}$ was administered to produce a neuromuscular block. Then, patient's lungs were ventilated manually with $100 \%$ oxygen. After $180 \mathrm{sec}$ of giving vecuronium, laryngoscopy was attempted and endotracheal intubation performed. After orotracheal intubation, further management of anesthesia and recording of hemodynamic parameters was done as per the protocol. In this study, different parameters were recorded, which includes systolic blood pressure (SBP), diastolic blood pressure (DBP), mean arterial pressure (MAP), heart rate $(\mathrm{HR})$ and $\mathrm{O} 2$ saturation $(\mathrm{SpO} 2)$ at 5 different time-points i.e. at baseline (T0), $60 \mathrm{sec}$ after dexmedetomidine infusion (T1), $60 \mathrm{sec}$ after induction (T2), $60 \mathrm{sec}$ after intubation (T3), 5 min after intubation (T4). To ensure the intubation quality controls, we have assessed the face mask ventilation, jaw relaxation, visibility of the vocal cords, position of the vocal cords and the reflex movement to tracheal intubation. The criteria used for ranking these variables were evaluated with the scoring system described by McNeil et al., 2000.

\section{Statistical analysis:}

Results were expressed as percentages and as the mean \pm standard error of the mean (SEM). Statistical evaluation was performed using MS-Excel and R statistical program (18). Unpaired t-test to compare quantitative variables and Chisquare test to compare qualitative traits between the different groups. The following symbols and the p-value cutoffs were used in this study. Non-significant $(\mathrm{P}>0.05) ; *(\mathrm{P} \leq 0.05)$; $* *(\mathrm{P} \leq 0.01)$ and $* * *(\mathrm{P} \leq 0.001)$

\section{Power Analysis for Sample Size Estimation}

This study aims to identify the differences between the two different doses of dexmedetomidine, therefore the effect size (the difference between the two groups) is expected to be 
minimal and so, we gave the effect size ' $d$ ' a value of 0.15 (usually 0.5 is considered small, 1 is considered moderate and 1.5 is considered high). To detect the differences between the two dosages with a small difference in potency, the statistical power needs to be high and hence we used the power of $85 \%$ along with a confidence interval of $95 \%$ to ensure the obtained differences if any are not by chance. With these parameters, the estimated sample size to be used in this study is 28 patients per group i.e. 56 patients in total. However, taken into consideration the estimated dropout rate of approximately $5 \%$ either due to the patients' unwillingness in the last minute to participate in the study or due to some other practical errors, the corrected sample size is calculated by the formula Corrected sample size $=$ Sample size/(1- [\% attrition/100]), which is equal to $56 /[1-(5 / 100)]=$ 58.94 which finally comes to 30 patients per group. Power analysis was performed using $\mathrm{G}^{*}$ Power 3 software. ${ }^{[19]}$

\begin{tabular}{|c|c|c|}
\hline \multicolumn{2}{|c|}{ Intubation condition scoring system } & \multirow[b]{2}{*}{ Score } \\
\hline Intubation characterstics & Criteria & \\
\hline \multirow[t]{2}{*}{ Jaw mobility } & $\begin{array}{l}\text { mobile } \\
\text { partially mobile }\end{array}$ & $\begin{array}{l}1 \\
2\end{array}$ \\
\hline & immobile & 3 \\
\hline \multirow[t]{2}{*}{ Mask ventilation } & $\begin{array}{c}\text { easy } \\
\text { difficult }\end{array}$ & $\begin{array}{l}1 \\
2\end{array}$ \\
\hline & immpossible & 3 \\
\hline \multirow[t]{2}{*}{ Vocal cord visibility } & $\begin{array}{c}\text { fully accessible } \\
\text { partially accessible }\end{array}$ & $\begin{array}{l}1 \\
2\end{array}$ \\
\hline & inaccessible & 3 \\
\hline \multirow[t]{2}{*}{ Vocal cord position } & $\begin{array}{c}\text { open } \\
\text { mid-position }\end{array}$ & $\begin{array}{l}1 \\
2\end{array}$ \\
\hline & closed & 3 \\
\hline \multirow[t]{2}{*}{ Patient movement } & $\begin{array}{l}\text { No movement during intubation } \\
\text { One or two coughs during intubation }\end{array}$ & $\begin{array}{l}1 \\
2\end{array}$ \\
\hline & $\begin{array}{l}\text { Persistent coughing and purposeful } \\
\text { movement }\end{array}$ & 3 \\
\hline
\end{tabular}

Figure 1: Table describing the Intubating conditions scoring system used in this study.

\section{Results}

In this study, we have determined the optimal dosage of dexmedetomidine along with the usage of a robust intubation condition scoring system. This study was conducted on a total of 60 patients belonging to ASA class I and II. They were further randomized and segregated into two groups i.e, Group I and Group II. Group I consist of 13 males and 17 females, whereas Group II comprises an equal number of patients from both the genders (15 each) [Figure 2]. Age distribution of the patients is broad in both the groups, ranging from 18 years to 60 years [Figure 2]. The average age of the patients in group I and Group II are 35.70 years and 38.10 years, respectively. All the patients that participated in this study underwent surgical interventions requiring general anaesthesia. Moreover, the mean bodyweight of the patients from both the groups is highly comparable $(\mathrm{P}$-value $=0.326)$, with average values of 63.13 \pm 10.29 and $61.97 \pm 9.58$ in Group I and Group II, respectively (mean \pm S.D) [Figure 2]. Both the groups were well-matched for their demographic data.

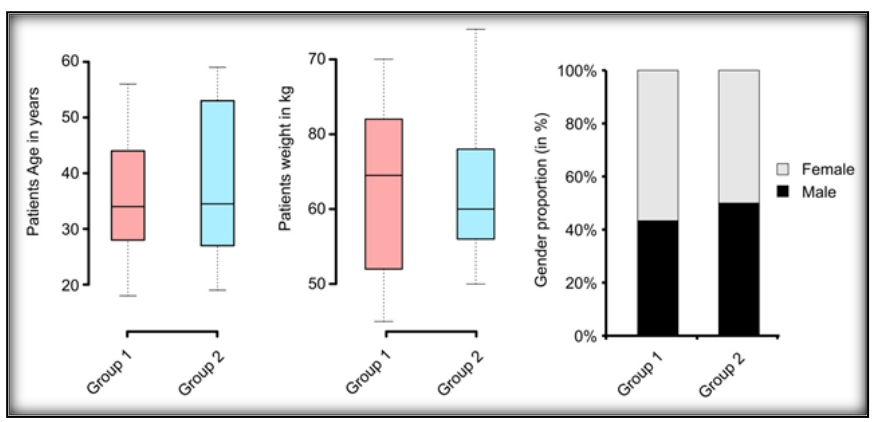

Figure 2: Boxplots and the percentage barplot depicting the age, weight and gender distribution of patients in two groups.

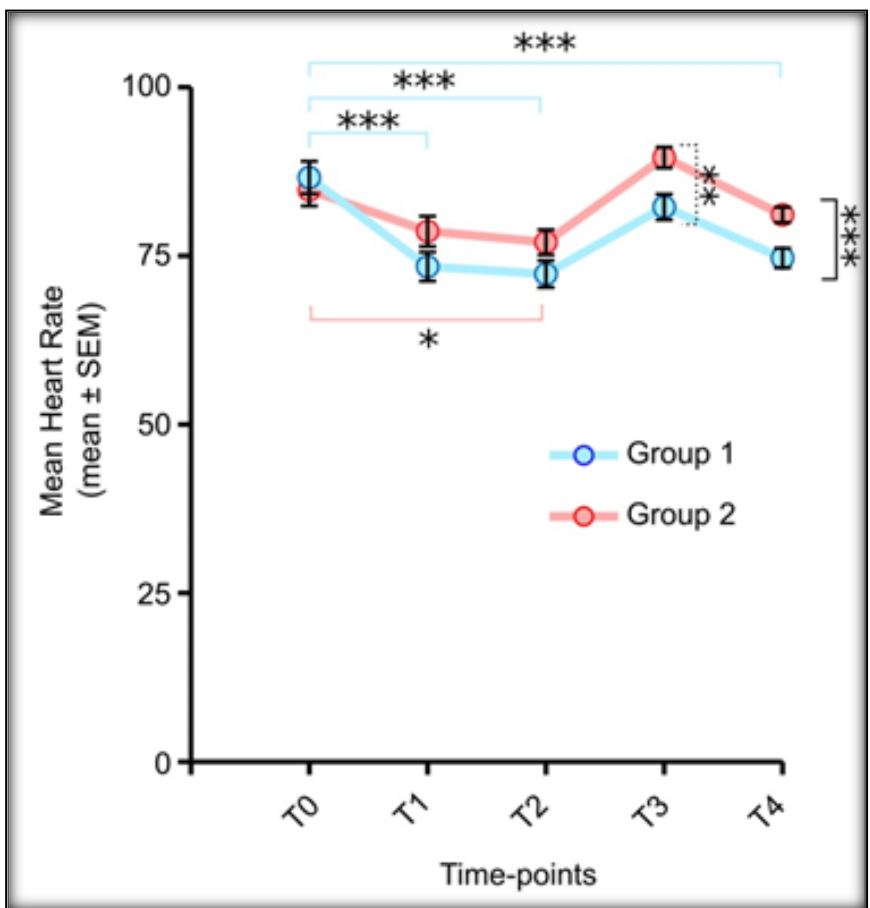

Figure 3: Scatterplot representation depicting the changes in the mean heart-rate (mean \pm standard error of mean) across the 5 different time-points in both the groups. Non-significant $(P>$ $0.05) ; *(\mathbf{P} \leq 0.05) ; * *(\mathbf{P} \leq 0.01)$ and $* * *(\mathbf{P} \leq 0.001)$.

Group I and Group II patients were given two different dosages of dexmedetomidine i.e $1 \mu \mathrm{g} / \mathrm{Kg}$ and $0.5 \mu \mathrm{g} / \mathrm{Kg}$ of the body weight, respectively. Prior to the administration of the drug, the baseline heart rates were recorded and no statistical differences were observed between the two groups $\left(\mathrm{T}_{0}\right.$; baseline measurement) [Figure 3]. In order to effectively compare the impact of dexmedetomidine on the pressor response, we evaluated different parameters across four-time points during the procedure $\left(T_{1}, T_{2}, T_{3}\right.$ and $\left.T_{4}\right)$. $T_{1}$ refers to the time point 60 seconds after the infusion of dexmedetomidine. $T_{2}$ represents the time point 60 seconds post-induction, whereas $T_{3}$ refers to time point 60 seconds post-intubation. $\mathrm{T}_{4}$, the last time point, refers to 5 minutes post-intubation. Statistical analyses of the intra/inter-group comparisons revealed that the mean heart rates were significantly higher in patients from Group II with respect to 
Group I patients. Within each group, the relative changes in the heart rate across different time points were similar. In a group $\mathrm{I}$, the mean heart rates during $\mathrm{T}_{1}, \mathrm{~T}_{2}$ and $\mathrm{T}_{4}$ were significantly lower with respect to the baseline measurement ( $\mathrm{P}<0.001$ for $\mathrm{T}_{1}$ vs $\mathrm{T}_{0}, \mathrm{~T}_{2}$ vs $\mathrm{T}_{0}, \mathrm{~T}_{4}$ vs $\mathrm{T}_{0}$ ). In Group II, similar trends were observed, although the difference was apparent only at $T_{2}(\mathrm{P}<0.05)$ [Figure 3]. This suggests that the administration of dexmedetomidine results in a transient decrease in the mean heart rate in both the groups with more prominent effects in Group I patients receiving $1 \mu \mathrm{g} / \mathrm{Kg}$ of dexmedetomidine.

Next, we also have evaluated the effect of dexmedetomidine administration on both systolic and diastolic blood pressure (SBP and DBP) variation across the indicated time points. Similar to the heart rate, we observed an initial transient decrease in the mean values of both SBP and DBP. However, in the case of SBP, we observed a significant difference at $\mathrm{T}_{1}, \mathrm{~T}_{2}$ and $\mathrm{T}_{4}(\mathrm{P}<0.001)$ in Group $\mathrm{I}$ patients and at $\mathrm{T}_{2}$ $(\mathrm{P}<0.05), \mathrm{T}_{3} \quad(\mathrm{P}<0.001)$ in Group II patients. In the case of DBP, we observed a significant difference at $\mathrm{T}_{1}(\mathrm{P}<0.05)$, $\mathrm{T}_{2}(\mathrm{P}<0.05)$, and $\mathrm{T}_{4}(\mathrm{P}<0.001)$, in Group 1 patients and at only $\mathrm{T}_{3}(\mathrm{P}<0.01)$, in Group II patients [Figure 4]. In addition, we have also evaluated the mean arterial pressure (MAP) changes in response to laryngoscopy and intubation, followed by the administration of dexmedetomidine in Group I and Group II patients. We have observed an overall decrease in MAP in Group I patients compared to Group II patients, although the significance was observed only at $\mathrm{T}_{4}$ in inter-group comparisons. However, in the intra-group comparisons, Group I patients showed a significant decrease in MAP at $\mathrm{T}_{1}, \mathrm{~T}_{2}, \mathrm{~T}_{4}(\mathrm{P}<0.01)$ while in Group II patients, the significance was observed only at $\mathrm{T}_{3}(\mathrm{P}<0.001)$ [Figure 5]. In order to estimate the changes in the blood oxygen levels upon dexmedetomidine administration during the procedure, we evaluated the mean SpO2 (peripheral capillary oxygen saturation) levels and compared within and between the two groups. Inter-group comparison revealed no differences across any time point. However, intra-group comparisons revealed that in Group I patients, a significant difference was observed at $\mathrm{T}_{2}(\mathrm{P}<0.01), \mathrm{T}_{3}(\mathrm{P}<0.001)$ and $\mathrm{T}_{4}(\mathrm{P}<0.001)$. Among the Group II patients, significance was observed across all the time points, $\mathrm{T}_{1}(\mathrm{P}<0.05)$ and $\mathrm{T}_{2}, \mathrm{~T}_{3}, \mathrm{~T}_{4}$ $(\mathrm{P}<0.001)$ [Figure 6].

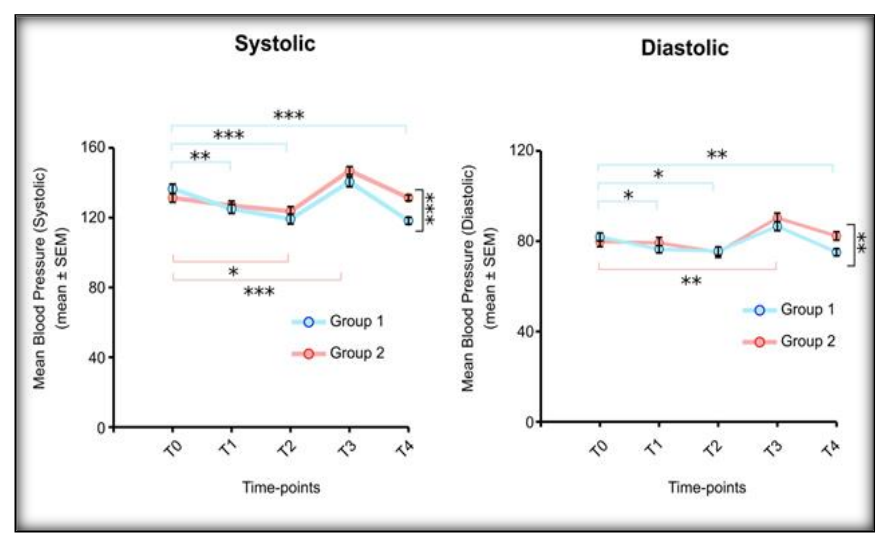

Figure 4: Scatterplot representation depicting the changes in the mean systolic and diastolic blood pressure (mean \pm standard error of mean) across the 5 different time- points in both the groups. Non-significant $(P>0.05) ; *(P \leq 0.05) ; * *(P \leq 0.01)$ and $* * *(\mathbf{P} \leq \mathbf{0 . 0 0 1})$.
Assessment of quality of intubation was done in accordance with McNeil et al., 2000 with minor modifications. To compare the quality of intubation, criteria jaw mobility, mask ventilation, vocal cord visibility, vocal cord position and patient movement were assessed in both groups. None of the patients got the scoring of 3 . Both groups were comparable in view of the above criteria as the p-value was $0.244,0.393$, $0.369,0.500$ and 0.081 , respectively [Figure 7]. In our study, no patient required atropine. No other side effects were seen as dexmedetomidine was given via slow intravenous infusion.

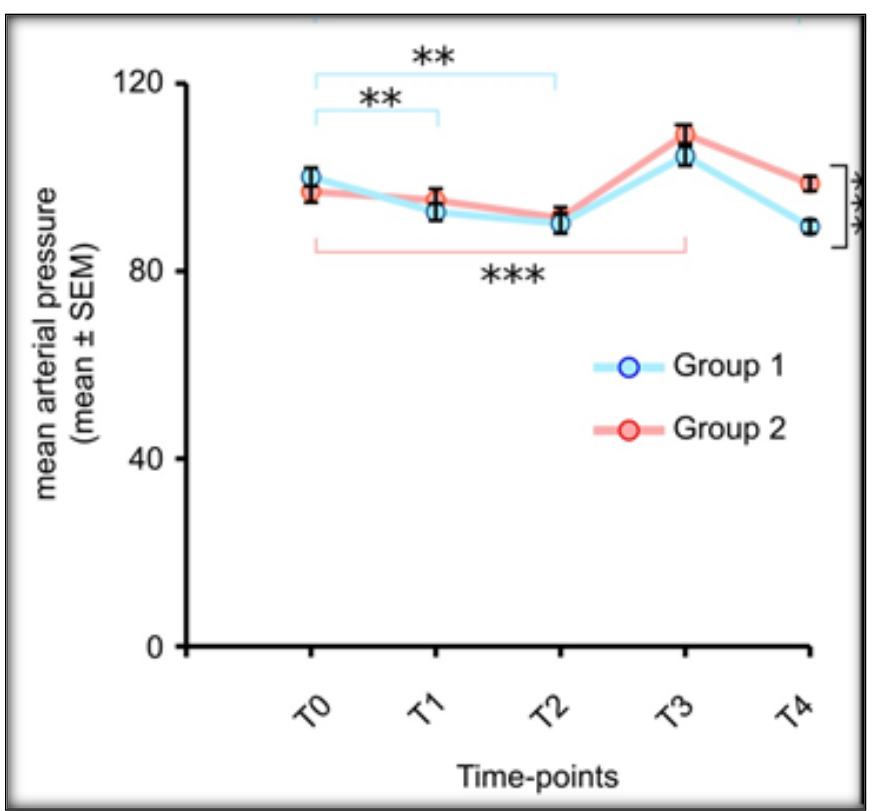

Figure 5: Scatterplot depiction of the changes in the mean atrial pressure (mean \pm standard error of the mean) across the 5 different time-points in both the groups. Non-significant $(P>$ $0.05) ; *(\mathrm{P} \leq 0.05) ; * *(\mathrm{P} \leq 0.01)$ and $* * *(\mathrm{P} \leq 0.001)$.

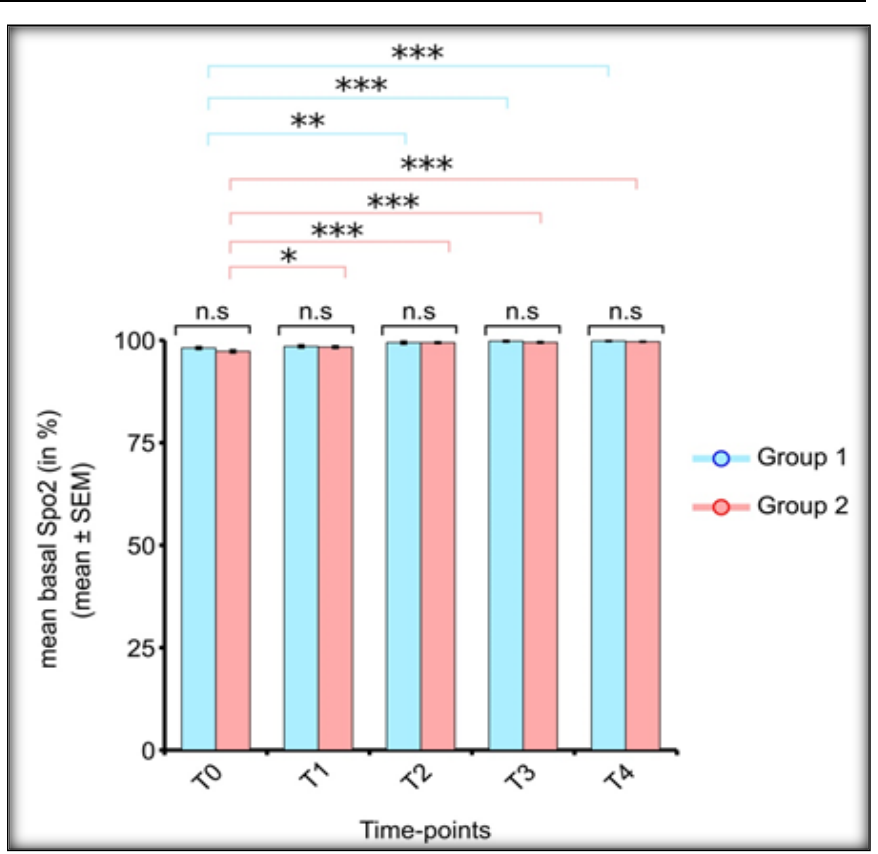

Figure 6: Percentage bar graph depiction of the relative changes in the mean basal SpO2 levels (mean \pm standard error of the mean) across the 5 different time-points in both the groups. Non-significant $(\mathrm{P}>0.05) ; *(\mathrm{P} \leq \mathbf{0 . 0 5}) ; * *(\mathrm{P} \leq \mathbf{0 . 0 1})$ and $* * *(\mathbf{P} \leq \mathbf{0 . 0 0 1})$. 


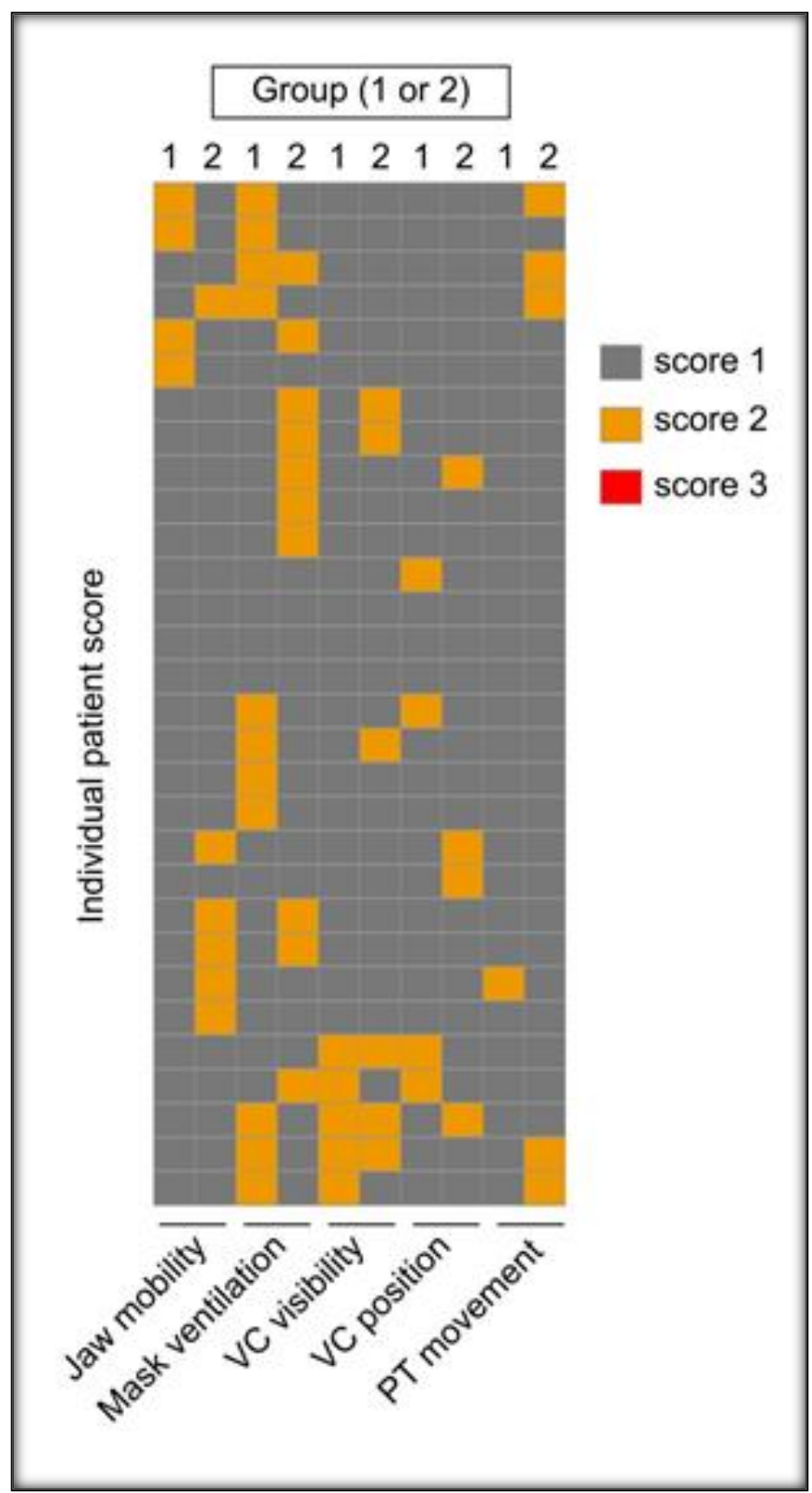

Figure 7: Heatmap representing the results of the intubating conditions scoring system across all patients in both groups. Scores are represented as colors, and each rectangular box represents a single patient score. Noteworthy, none of the patients have obtained a score of 3 .

\section{Discussion}

Laryngoscopy and endotracheal intubation are the most commonly used procedures by anaesthesiologists all over the world. However, these procedures are associated with an increased heart rate, systemic blood pressure and other associated phenomena commonly known as 'pressor responses,' which can be detrimental to the patients with cardiovascular disorders. ${ }^{[20]}$ Dexmedetomidine, a preanesthetic drug, is a widely used agent for laryngoscopy and intubation procedures. Various studies have used dexmedetomidine in doses ranging from $0.1-10 \mu \mathrm{g} / \mathrm{kg} / \mathrm{hr}$ but the effective loading dosage and the optimal infusion rate of the drug, which minimizes the pressor response in patients is not conclusive. The most common side effects of dexmedetomidine are hypotension and bradycardia that occur more frequently during the loading period. In 2001, Venn et al. and others had shown that the side effects of dexmedetomidine were not observed when $2.5 \mu \mathrm{g} / \mathrm{kg}$ loading dose of dexmedetomidine was administered in $10 \mathrm{~min}$ and followed by an infusion rate of $0.2-0.5 \mu \mathrm{g} / \mathrm{kg} / \mathrm{min} .^{[21,22]}$ Recent reports suggest that reducing the dose of dexmedetomidine to $1 \mu \mathrm{g} / \mathrm{kg}$ of body weight and using a slower infusion rate of the drug have beneficial effects in controlling the hemodynamic fluctuations during the intubation. ${ }^{[23]}$

In our study, we show that the patients from ASA Grade I and II showed relatively better hemodynamic stability when pre-treated with dexmedetomidine at a dosage of $1 \mu \mathrm{g} / \mathrm{kg}$ of body weight in comparison to those who received $0.5 \mu \mathrm{g} / \mathrm{kg}$ of the drug, prior to anesthesia. Although the similar comparative effect has been previously shown, we have used a more systematic approach by incorporating the scoring system of the patients' responses based on the parameters shown in McNeil et al., 2000, ${ }^{[24]}$ and accordingly classified the effect of dexmedetomidine on the pressor response. Although no observational differences were found between the groups of patients receiving different doses of dexmedetomidine on the basis of our intubation control scoring system, our approach provides a better measure of the effect of drugs in attenuating the hemodynamic instabilities during laryngoscopy and intubation.

In addition, we also minimized the duration of the laryngoscopy and intubation and performed the procedure within 15 seconds to tone down the pressor response as shown by, ${ }^{[6]}$ However, prior to the procedure, we did not evaluate the level of catecholamine which is indicative of the patient's stress and also, we did not check for the basal cardiac index before the drug treatment. The average duration of fasting was confirmed to be around 6 hours by the patients, although the actual durations of each individual were not taken into consideration in this study.

\section{Conclusion}

Our results suggest that dexmedetomidine, when applied at a dose of $1.0 \mu \mathrm{g} / \mathrm{kg}$ body weight given before induction, significantly obtunds the hemodynamic responses to laryngoscopy and tracheal intubation compared to dexmedetomidine $(0.5 \mu \mathrm{g} / \mathrm{kg}$ body weight $)$ in the patients from ASA Grade I and II.

\section{References}

1. Derbyshire DR, Chmielewski A, Fell D, Vater M, Achola K, Smith G. Plasma catecholamine responses to tracheal intubation. Br J Anaesth. 1983;55(9):855-60.

2. Caceres JA, Goldstein JN. Intracranial Hemorrhage. Emergency medicine clinics of North America. 2012;30(3):771-775.

3. Fox EJ, Sklar GS, Hill CH, Villanueva R, King BD. Complications related to the pressor response to endotracheal intubation. Anesthesiology. 1977;47(6):524-525.

4. Hanada S, Kawakami H, Goto T, Morita S. Hypertension and anesthesia. Curr Opin Anaesthesiol. 2006;19(3):315-319.

5. Jarineshin H, Kashani S, Vatankhah M, Abdulahzade Baghaee A, Sattari S, Fekrat F. Better Hemodynamic Profile of Laryngeal Mask Airway Insertion Compared to Laryngoscopy and Tracheal Intubation. Iran Red Crescent Med J. 2015;17(8):e28615. 
6. Stoelting RK. Circulatory changes during direct laryngoscopy and tracheal intubation: influence of duration of laryngoscopy with or without prior lidocaine. Anesthesiology. 1977;47(4):381-4.

7. Black TE, Kay B, Healy TE. Reducing the hemodynamic responses to laryngoscopy and intubation. A comparison of alfentanil with fentanyl. Anesthesia. 1984;39(9):883-887.

8. Jabbour-Khoury SI, Dabbous AS, Rizk LB, Abou Jalad NM, Bartelmaos TE, El-Khatib MF et al. A combination of alfentanillidocaine-propofol provides better intubating conditions than fentanyllidocaine-propofol in the absence of muscle relaxants. Can J Anaesth. 2003;50(2):116-20.

9. Devys JM, Mourissoux G, Donnette FX, Plat R, Schauvliège F, Le Bigot $\mathrm{P}$, et al. Intubating conditions and adverse events during sevoflurane induction in infants. Br J Anaesth. 2011;106(2):225-9.

10. Puri GD, Batra YK. Effect of nifedipine on cardiovascular responses to laryngoscopy and intubation. Br J Anaesth. 1988;60(5):579-81.

11. Nishikawa $T$, Namiki A. Attenuation of the pressor response to laryngoscopy and tracheal intubation with intravenous verapamil. Acta Anaesthesiol Scand. 1989;33(3):232-5.

12. Li D, Lu H, Li X, Quan Q, Li X, Lu W. Calcium channel blockers in cirrhotic patients with portal hypertension. Chin Med J. 1995;108(11):803-8.

13. McCammon RL, Hilgenberg JC, Stoelting RK. Effect of propranolol on circulatory responses to induction of diazepam-nitrous oxide anesthesia and to endotracheal intubation. Anesth Analg. 1981;60(8):579-83.

14. Gore MS, Harnagale KD. Evaluation of Intubating Conditions with Varying Doses of Propofol without Muscle Relaxants. Journal of Anaesthesiology, Clinical Pharmacology. 2011;27(1):27.

15. Yuan L, Chia YY, Jan KT, Chen CS, Wang CH, Haung LH et al. The effect of single bolus dose of esmolol for controlling the tachycardia and hypertension during laryngoscopy and tracheal intubation. Acta Anaesthesiol Sin. 1994;32(3): 147-152.

16. Grant S, Noble S, Woods A, Murdoch J, Davidson A. Assessment of intubating conditions in adults after induction with propofol and varying doses of remifentanil. British Journal of Anaesthesia. 1998;81(4):540-3.

17. Afonso J, Reis F. Dexmedetomidine: Current Role in Anesthesia and Intensive Care. Brazilian Journal of Anesthesiology. 2012;62(1):11833.

18. R: a language and environment for statistical computing [Internet]. [cited 2018 Aug 4]. Retrieved from: http://www.R-project.org.

19. Faul F, Erdfelder E, Buchner A, Lang A-G. Statistical power analyses using G*Power 3.1: Tests for correlation and regression analyses. Behavior Research Methods. 2009;41(4):1149-60.

20. Prys-Roberts C, Greene LT, Meloche R, Foëx P. Studies of anaesthesia in relation to hypertension. II. Haemodynamic consequences of induction and endotracheal intubation. Br J Anaesth. 1971;43(6):53147.

21. Venn RM, Grounds RM. Comparison between dexmedetomidine and propofol for sedation in the intensive care unit: patient and clinician perceptions. Br J Anaesth. 2001;87(5):684-90.

22. Afshani N. Clinical application of dexmedetomidine. Southern African Journal of Anaesthesia and Analgesia. 2010;16(3):50-6.

23. Shin HW, Yoo HN, Kim DH, Lee H, Shin HJ, Lee HW. Preanesthetic dexmedetomidine $1 \mu \mathrm{g} / \mathrm{kg}$ single infusion is a simple, easy, and economic adjuvant for general anesthesia. Korean J Anesthesiol. 2013;65(2):114-20.

24. McNeil IA, Culbert B, Russell I. Comparison of intubating conditions following propofol and succinylcholine with propofol and remifentanil 2 micrograms kg-1 or 4 micrograms kg-1. Br J Anaesth. 2000;85(4):6235 .

Copyright: () the author(s), 2020. It is an open-access article distributed under the terms of the Creative Commons Attribution License (CC BY 4.0), which permits authors to retain ownership of the copyright for their content, and allow anyone to download, reuse, reprint, modify, distribute and/or copy the content as long as the original authors and source are cited.

How to cite this article: Varhney N, Agrawal T, Sharma R, Nangia SK, Mangwana P. Systematic Approach to Evaluate the Potential of Dexmedetomidine in Attenuating the Pressor Response and the Quality of Intubation during Laryngoscopy. Acad. Anesthesiol. Int. 2020;5(1):156-161.

DOI: dx.doi.org/10.21276/aan.2020.5.1.32

Source of Support: Nil, Conflict of Interest: None declared. 